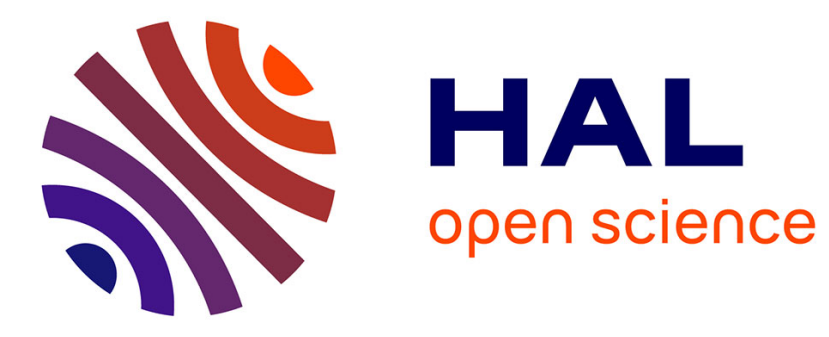

\title{
Functional Vision Analysis in Patients With CHARGE Syndrome
}

Gilles C Martin, Matthieu P Robert, Georges Challe, Nhung Th Trinh, Tania Attie-Bitach, Bahram Bodaghi, Dominique Brémond-Gignac, Véronique Abadie

\section{To cite this version:}

Gilles C Martin, Matthieu P Robert, Georges Challe, Nhung Th Trinh, Tania Attie-Bitach, et al.. Functional Vision Analysis in Patients With CHARGE Syndrome. Journal of Pediatric Ophthalmology and Strabismus, 2020, 57 (2), pp.120-128. 10.3928/01913913-20200207-02 . hal-02995263

\section{HAL Id: hal-02995263 https://hal.sorbonne-universite.fr/hal-02995263}

Submitted on 9 Nov 2020

HAL is a multi-disciplinary open access archive for the deposit and dissemination of scientific research documents, whether they are published or not. The documents may come from teaching and research institutions in France or abroad, or from public or private research centers.
L'archive ouverte pluridisciplinaire HAL, est destinée au dépôt et à la diffusion de documents scientifiques de niveau recherche, publiés ou non, émanant des établissements d'enseignement et de recherche français ou étrangers, des laboratoires publics ou privés. 
3 Gilles C. MARTIN ${ }^{1,2}$, MD; Matthieu P. ROBERT ${ }^{3,4}$, MD-PhD; Georges CHALLE ${ }^{2,5}$, MD;

4 Nhung TH. TRINH ${ }^{6}$; Tania ATTIE-BITACH ${ }^{7,8,9}$, MD-PhD; Dominique BRÉMOND-

5 GIGNAC $^{3,8}$; MD-PhD, Bahram BODAGHI ${ }^{2,5}$, MD-PhD; Véronique ABADIE ${ }^{8,9,10}$, MD-

$6 \mathrm{PhD}$

7 Institutions :

8 1. Fondation Ophtalmologique A. de Rothschild, 25-29 Rue Manin, 75019 Paris, France

9 2. Sorbonne University, Paris, France

10 3. Ophthalmology Department and Rare Ophthalmological Diseases Reference Centre

11 (OPHTARA), Necker-Enfants Malades University Hospital, AP-HP, 149 Rue de Sèvres,

1275015 Paris, France

13 4. Cognition and Action Group (COGNAC-G), UMR 8257, CNRS-SSA-Paris Descartes

14 University, Sorbonne Paris Cité, 45 Rue des Saint Pères, 75006 Paris, France

15 5. Ophthalmology Department, DHU Vision and Handicaps, La Pitié-Salpétrière University

16 Hospital, AP-HP, 47-83 Boulevard de l'Hôpital, 75013 Paris, France.

17 6. Inserm UMR 1153, Obstetrical, Perinatal and Pediatric Epidemiology Research Team,

18 Research Centre for Epidemiology and Biostatistics Sorbonne Paris Cité (CRESS), Paris

19 Descartes University, Paris, France

20 7. Genetic Department, Necker-Enfants Malades University Hospital, AP-HP, 149 Rue de

21 Sèvres, 75015 Paris, France

22 8. Paris Descartes University, Sorbonne Paris Cité, 45 Rue des Saint Pères, 75006 Paris,

23 France

24 9. Imagine Institute, IHU, Paris, France

25 10. Pediatrics Department. Necker-Enfants Malades University Hospital, AP-HP, 149 Rue

26 de Sèvres, Paris, France. 


\section{Corresponding Author: Gilles C. MARTIN}

28 Ophthalmology Department, Fondation A. de Rothchild, 25-29 Rue Manin, 75019 Paris,

29 France

30 gillesmartin88@gmail.com;

31 Phone: +33148036565

32

33 E-mail of the authors: matthieu.robert@aphp.fr, georges.challe@gmail.com;

34 nhungtrinh0401@gmail.com; tania.attie@inserm.fr; dominique.bremond@ aphp.fr;

35 bahram.bodaghi@aphp.fr; veronique.abadie@aphp.fr

36

37 Word count: 2912/4000 


\section{Acknowledgments:}

39 We thank all the patients and families for their participation. We are thankful to Ms Wiam

40 BHIA for her help in collecting consent forms, to Prof. Martin CHALUMEAU for his

41 review of the manuscript, and to Ms Charlotte CREUX for her precious help in creating the

42 questionnaire. We thank Ms Laura SMALES for helping with editing and English writing. 


\section{Abstract:}

44 Purpose: CHARGE syndrome (CS) is a multiple malformative syndrome in which ocular

45 colobomas cause visual impairment. Data are lacking regarding visual function because

46 classical methods for visual acuity (VA) assessment are often not applicable in patients with

47 CS. We evaluated vision in a pilot study of patients with CS by using a new questionnaire

48 entitled VISIOCHARGE.

49 Methods: Ophthalmological data including fundus description and VA, when available, 50 were extracted from charts of 83 patients with CS, and VISIOCHARGE was prospectively 51 sent to 55 of them. The answers of the 36 responders (18 males) allowed for calculating 3

52 scores assessing distance-vision, near-vision, and an "overall ability” score.

53 Results: Visual acuity measurements were extracted from the charts of 20 of the 36 patients.

54 The mean VA was 20/50. The mean distance-vision score of 0.62 (SD 0.30) and near-vision 55 score of 0.78 (SD 0.23 ) were correlated with VA in the 20 patients $(\rho=0.64, \mathrm{p}=0.002$ and $56 \rho=0.61, \mathrm{p}=0.005$, respectively) and were associated with the severity of the colobomatous 57 malformation ( $\mathrm{p}=0.049$ and $\mathrm{p}=0.008$, respectively). Severity of the ocular malformation was 58 not associated with overall ability score $(\mathrm{p}=0.64)$.

59 Conclusions: VISIOCHARGE is feasible in patients with CS and may help in the 60 assessment of visual function. The mean VA and the answers to the questionnaire showed 61 relatively good visual skills in these patients in everyday life, even in those with bilateral 62 colobomas, which contrasts with the pessimistic conclusions usually resulting from the 63 initial fundus examination.

65 Number of words: 238/250 


\section{INTRODUCTION}

70 CHARGE syndrome (CS) is a multiple malformative syndrome, with coloboma representing

71 a major feature and diagnostic criterion ${ }^{1,2}$. This ocular anomaly is found in $72 \%$ to $95 \%$ of

72 patients with $\mathrm{CS}^{3-8}$ and represents an important cause of disability in affected patients.

73 However, previous studies mainly focused on the anatomical aspects of the ocular

74 manifestation of the syndrome and rarely reported results from visual acuity (VA) and/or

75 visual function assessment. This lack of data is due in part to the difficulty in obtaining a

76 reliable VA value in many patients with $\mathrm{CS}$, as classical ophthalmological evaluation

77 methods are often not applicable because of the multiple sensory deficits and/or cognitive

78 disabilities of such patients. The few series reporting VA in CHARGE syndrome found

79 mean values below 20/60 $4-8$. However, in our experience, the parents, relatives and

80 professionals caring for these patients often report good visual skills in everyday life, which

81 contrasts with the often pessimistic conclusions from the ophthalmological examinations, in

82 particular neonatal examinations. This contrast points out the need for a new tool to assess

83 the real visual function in patients with CS regardless of the severity of their sensory, motor

84 and/or cognitive impairments.

85 In this study, we aimed to develop an original self-administered questionnaire designed for

86 patients with CS (VISIOCHARGE) and we used it to evaluate the functional vision of

87 patients with CS. The other goals were to describe the ocular features of a large series of

88 patients with CS, to analyze the links between the severity of the ocular malformation and

89 practical visual function and to confirm the previously suspected correlation between visual

90 impairment and poor developmental milestones in these children ${ }^{9,10}$. 


\section{PATIENTS \& METHODS}

\section{Questionnaire development}

95 The questionnaire, entitled VISIOCHARGE (see Appendix) was built from observations and 96 comments of pediatricians, ophthalmologists and orthoptists used to following up patients

97 with CS. A first version of the questionnaire was randomly sent to 4 families to obtain their

98 comments on its quality, feasibility and understandability. After a review, we adopted a final

99 version of the questionnaire consisting of 30 items in 3 categories: 1) parental evaluation of 100 global vision (2 items), designed to assess parents' feeling about the importance of the visual

101 impairment of their child and its consequences on everyday life; 2) evaluation of distance

102 vision (9 items); and 3) evaluation of near vision (10 items). Additional questions were

103 asked to evaluate the ophthalmological follow-up (4 items), educational level and age of

104 walking acquisition of the patient (5 items). Some free space was available at the end of the

105 document for open answers and comments.

107 Study population

108 All patients with CS followed or seen at least once between January 1, 1990 and December

10931,2016 in the pediatric and/or ophthalmologic departments of Necker-Enfants Malades

110 Hospital and/or La Pitié-Salpétrière Hospital were included. CS diagnosis was established

111 clinically by using the Blake and Verloes criteria ${ }^{1,2}$. When available, their CHD7 mutation

112 status was extracted from medical charts. The VISIOCHARGE questionnaire was sent by

113 mail between January 1 and December 31, 2017 to the most recent address of the patient

114 registered in the hospital database, accompanied by an information letter and a consent form.

115 The patients, or their parents in case of inability to read and/or to understand the questions,

116 were asked to complete the questionnaire and return it by mail to the investigator with a

117 signed consent form. A few days after sending the questionnaire, investigators contacted the

118 patients or their parents by phone call to further explain the aim of the study and answer their 
119 questions. Patients with CS who had died before the beginning of the study were excluded

120 and their parents were not asked for participation. This study was approved by the ethics

121 committee of Necker-Enfants Malades Hospital on October 31, 2016 (authorization number:

122 2016-VA 24-R1), and adhered to the tenets of the Declaration of Helsinki.

124 Data collection and outcome measures

125 The following information was extracted from medical charts of patients: the most recent 126 corrected best binocular VA, the description of fundus of each eye after dilation (presence of

127 chorioretinal and/or optic disk coloboma, involvement of the fovea and/or the optic disk

128 inside the coloboma), and presence of nystagmus, strabismus, and any other anomalies seen

129 during the ophthalmological examination, including ptosis, facial palsy, congenital cataract

130 or retinal detachment.

131 VA was measured by using the French Monoyer chart and was expressed in decimal, 132 fraction (in feet) and LogMAR units.

133 On the basis of data from the medical chart, we assigned patients to two groups based on the

134 severity of anatomical lesions. Group A included patients with no coloboma in both eyes or

135 with a coloboma in one or both eyes but at least one eye having a fully preserved optic disk 136 and fovea. Group B included patients with a coloboma involving the optic disk in both eyes,

137 with or without involvement of the fovea.

138 Answers to each item of the questionnaire were analyzed independently to detail the visual

139 ability. We then calculated three scores by giving a value in points for the different items;

140 the maximum score corresponded to the most difficult or smallest things to see. The three

141 scores calculated were a distance-vision score, a near-vision score, and an overall ability

142 score. The overall ability score combined the answers to six items exploring the ability to

143 perform six tasks: watch TV, move around indoors in a familiar place, move around indoors 
144 in an unknown place, move around outdoors, use a tablet PC, use a smartphone. The scores

145 were expressed as decimals between zero and one.

146 To simply assess the psychomotor development of patients, the questionnaire asked about

147 the age of walking acquisition, which was verified in medical charts, and the most recently

148 attended educational structure. These educational structures were classified from level 1 to 5,

149 reflecting the communication and cognitive abilities of the patients: 1) in a regular school

150 without any specific assistance; 2) with an assistant dedicated to the child in a regular

151 school; 3) in a specific classroom and/or structure for deaf and/or blind children, without

152 cognitive disabilities; 4) in a structure dedicated to deaf and/or blind children with cognitive

153 impairment but communication abilities; and 5) severe cognitive disabilities without any

154 acquired language and poor learning.

155

156 Statistics

157 Continuous variables were expressed as mean with standard deviation (SD). Because the

158 sample was too small, we could not divide the ophthalmological gravity of patients into

159 more than two groups for analyzing the correlation between anatomic and functional data.

160 We compared groups by Kruskall Wallis, Mann-Whitney and Fisher tests, and used the

161 Spearman for correlations. Significance was considered at two-sided $p<0.05$.

\section{RESULTS}

164 The database review found 83 patients (46 males) followed in the two centers for typical CS

165 with or without ophthalmological involvement. Among the 83 patients, 10 were deceased 166 and 18 were followed elsewhere. Thus, we sent the VISIOCHARGE questionnaire to 55

167 patients included in the prospective part of the study. Four questionnaires were returned

168 because of a wrong address, and 15 families received the letter but did not answer or refused

169 to take part in the study. Finally, among the 55 solicited patients, 36 (18 males) with 
170 completed VISIOCHARGE questionnaires were included in the analysis (response rate $=$

$17166 \%$ ). The mean age of responders was 13.8 years (SD 6.9). The demographic,

172 ophthalmological and neurodevelopmental characteristics of the 36 responders were

173 comparable to those of the 83 patients in the whole series (Table 1) allowing for discussion

174 and conclusions. A mutation in CHD7 was found in 31 children of the 33 investigated

175 patients (94\%). The genetics investigation had not been performed for 3 others.

176 Of the 36 patients, $32(89 \%)$ had at least one ocular coloboma of the posterior segment 177 reported in their medical chart; $4 / 32(11 \%)$ had presented a unilateral retinal detachment

178 (RD). Overall, 27/36 (75\%) patients wore glasses; the mean age at the first optical correction 179 was 4 years (SD 3.7).

181 Visual function and its consequences for activities of daily life

182 Of the 36 patients, only $20(56 \%)$ had VA data available in medical charts. In these patients,

183 the mean VA was 0.42 (20/50, 0.40 LogMAR). When we excluded the only patient without

184 coloboma with a measurable VA, the mean VA stayed similar (0.40 LogMAR). For 26/36

$185(72 \%)$ patients, their parents reported trouble related to the vision of their child; for $11 / 36$

186 (30\%), their child was declared to be "very bothered" by it (Table 2). Nevertheless, 32/36

$187(89 \%)$ patients were able to use electronic devices such as smartphones or digital tablets;

$18831 / 36(86 \%)$ were able to watch television, 22/36 (61\%) reported an ability to recognize a

189 familiar face at more than $2 \mathrm{~m}$, and 19/36 (53\%) were able to read or identify Arial

190 characters of 18 size at a reading distance of $40 \mathrm{~cm}$. The mean distance-vision, near-vision,

191 and overall ability scores were 0.62 (SD 0.30), 0.78 (SD 0.23) and 0.79 (SD 0.25), 192 respectively.

193 For the 20 patients with a VA measurement, the distance-vision and near-vision scores from

194 the VISIOCHARGE questionnaire were positively correlated with measured VA $(\rho=0.64$,

$195 \mathrm{p}=0.002$, and $\rho=0.61, \mathrm{p}=0.005$, respectively). Parental evaluation of the global vision of their 
196 child was correlated with the distance-vision and near-vision scores $\left(r_{s}=0.61, \mathrm{p}<0.001\right.$, and

$197 r_{s}=0.63, \mathrm{p}<0.001$, respectively $)$ and with measured VA $\left(r_{s}=0.68, \mathrm{p}<0.001\right)$

\section{Developmental features}

199 In this series, the mean age of walking acquisition was 35.4 months (SD 15.0). The distance-

200 vision score was negatively correlated with age of walking acquisition $(\rho=-0.38, \mathrm{p}=0.037)$.

201 Age of walking acquisition was not correlated with parental evaluation of the global vision

202 of their child or near-vision or overall ability score $\left(\mathrm{r}_{\mathrm{s}}=-0.22, \mathrm{p}=0.23 ; \rho=0.03, \mathrm{p}=0.86\right.$;

$203 \rho=0.02, p=0.92$, respectively). Regarding educational levels, most patients had been

204 schooled in structures of types 2, 3 and 4. The distance-vision, near-vision and overall ability

205 scores were all negatively correlated with educational level $\left(r_{s}=-0.54, \mathrm{p}<0.001 ; r_{s}=-0.45\right.$,

$206 \mathrm{p}<0.001 ; r_{s}=-0.39, \mathrm{p}=0.02$, respectively). Educational level was not correlated with parental

207 evaluation of the global vision of their child $\left(r_{s}=-0.27, \mathrm{p}=0.11\right)$.

\section{Correlation between anatomic and functional data}

210 Patients in group A (mild anatomical lesions, $\mathrm{n}=18$ ) were compared to those in group B

211 (severe anatomical lesions, $\mathrm{n}=17$ ) (Table 3). One patient was excluded from this analysis

212 because of an incomplete description of the fundus. As expected, the mean VA was

213 significantly worse for group B than group A patients: 0.23 (20/80, 0.64 LogMAR) vs 0.88

214 (20/25, 0.05 LogMAR), $\mathrm{p}<0.001$. Similarly, the mean distance-vision and near-vision scores

215 were significantly lower for group B than group A $(0.54$ vs $0.71, p=0.049$, and 0.69 vs 0.88 ,

$216 \mathrm{p}=0.008$, respectively). However, the 2 groups did not differ in parental evaluation of the

217 global vision of their child $(\mathrm{p}=0.07)$ or in the overall ability score from the questionnaire

218 (0.76 vs $0.83, \mathrm{p}=0.64)$. The two groups did not differ in developmental features. Taken

219 separately, the only two items showing a significant difference between the two groups were

220 those exploring the ability to recognize a familiar face at a given distance $(p=0.008)$ and the

221 smallest size of Arial text readable $(\mathrm{p}=0.03)$. 


\section{Comments from responders}

223 Ten (28\%) patients (or their parents) reported better performance in near vision than distance 224 vision. For $6(17 \%)$ patients, a photophobia was also spontaneously reported in

225 questionnaires. The parents of a young patient reported that at birth, their child had been 226 given a prognosis of severe vision, total blindness, after the first ophthalmological 227 examination because of the severity of the colobomas involving the fovea in both eyes. The 228 VA of this child was actually measured at $0.3(20 / 60,0.48$ LogMAR). His distance-vision, 229 near-vision and overall ability scores were $0.70,0.60$ and 1 , respectively. One patient 230 spontaneously highlighted a prosopagnosia (difficulty in recognizing faces out of their 231 context).

\section{DISCUSSION}

234 This series is one of the largest to describe the ocular features in CS, and the first to 235 specifically address the question of visual function, showing better visual skills than 236 previously reported. The most recent studies ${ }^{4,5,7}$ reported VA under 0.3 (20/60, 0.48 237 LogMAR) in $58 \%$ to $67 \%$ of patients with CS for whom VA was measurable, which 238 contrasts with the $30 \%$ in our series, closer to the $17 \%$ found by Russel-Eggit et al (6). 239 However, these comparisons are difficult to interpret because of the very small proportion of

240 patients in each series for whom VA was measurable. With 20 (56\%) patients having a 241 measured VA, our study is the first to report such a high proportion of available data.

242 However, the substantial number of missing data is also the main reason that led us to look

243 for another way to explore visual function in this specific population.

244 In the ophthalmological field, some examination methods exist to assess visual function in

245 non-verbal children who are very young or have intellectual impairment. Among them, the 246 preferential looking procedures ${ }^{11}$ (Cardiff Acuity Test, Teller Acuity Test), optokinetic 247 nystagmus assessment, and visual evoked potentials are the most commonly used. However, 
248 these tools are not widely available in routine care and may not be suitable for some patients

249 with CS because of cognitive disabilities reducing their attention or some ophthalmological

250 features such as oculomotor palsies or nystagmus, commonly found in this population.

251 Questionnaires assessing functional vision in the pediatric field are being increasingly used

252 to assess the consequences of the visual impairment on quality of life. We reviewed seven

253 available questionnaires ${ }^{12-18}$ but none were suitable for patients with CS because the

254 questions implied an absence of sensory, motor or cognitive disabilities besides the visual

255 impairment (Table 4). We found two questionnaires designed for children with

256 disabilities ${ }^{19,20}$. However, one was not appropriate for regular self-administered evaluation,

257 because some items seemed equivocal, whereas the other was specifically aimed at children

258 with severe cognitive disabilities, which is not a systematic feature of patients with CS.

259 Thus, we aimed to develop an original questionnaire, suitable for every patient, regardless of

260 the age or any motor and/or cognitive disability. VISIOCHARGE not only proved is

261 feasibility in a heterogenous population of patients with CS, but also demonstrated that most

262 of the patients with CS were able to perform similar tasks as other children. Most of the

263 patients were not very bothered by their visual impairment, especially in tasks involving near

264 vision. The main difficulties reported were in distance vision and outdoor activities.

265 VISIOCHARGE could reflect visual function because the distance-vision and near-vision

266 scores were well correlated with VA, when available. To confirm these results, this

267 questionnaire should be tested in other diseases featuring impaired visual function in

268 children with or without associated disabilities. Indeed, the main limitation of this study is

269 that this questionnaire has not been rigorously validated yet. Now that we have proven the

270 questionnaire's feasibility on a pilot population, its use in a much larger population is

271 possible, and its validation by evaluating its metrological qualities has to be done. Another

272 important limitation of the study is the risk of subjectivity, unavoidable with self-

273 administered questionnaires and perhaps more so when a relative performs it. However, 
274 because we wanted to assess visual skills in everyday life, we cannot totally suppress this

275 subjectivity.

276 With a total of 83 charts reviewed, our series is the largest to detail the ocular features in CS.

277 As previously described, the most frequent feature is chorio-retinal coloboma, found in $83 \%$

278 of our patients, close to the $82 \%, 79 \%$ and $90 \%$ of Russel-Eggit et al., Tellier et al. and

279 Strömland et al., respectively ${ }^{6-8}$. Retinal detachment was found in 4,4\% of colobomatous

280 eyes, in the low average of previously published data about RD complicating colobomas,

281 suggesting that CS may not be a risk factor for RD.

282 The correlation between anatomy and function is incomplete. Although VA and distance-

283 vision and near-vision scores were better in children with peripheral colobomas than those

284 with colobomatous lesions involving both the optic nerve and/or macula, the results from our

285 questionnaire did not find any difference between these patients in overall ability score and

286 parental evaluation of their global vision. This lack of correlation may be due in part to a

287 potential failure of our questionnaire to reveal a difference. However, these results confirm

288 the general impression of parents and caregivers that children with CS and large colobomas

289 can develop some surprising compensatory strategies, allowing them to use their remaining

290 vision, either central or peripheral. Another explanation for the lack of anatomic and

291 functional correlation is the difficulty for ophthalmologists to assess macular anatomy by

292 fundus examination alone, as it was previously shown ${ }^{21}$. Thus, as suggested by Nishina $e t$

$293 a l$, it seems crucial not to predict poor vision in a neonate with CS and bilateral coloboma

294 because our experience showed that some of these children can later show correct visual

295 function ${ }^{5}$.

296 Our series also confirmed the previously suspected association between visual function and

297 some developmental parameters ${ }^{9,10}$ independent of other manifestations of the syndrome.

298 Late acquisition of walking has been found negatively correlated with distance-vision score,

299 and educational level has also been correlated with all visual function scores. This 
300 observation reinforces the promotion of regular and rigorous ophthalmological care for every

301 patient with CS, regardless of the severity of the ocular malformation, to assure the best

302 visual prognosis as well as good general development.

303 Assessment of visual function in patients with CS may be challenging because VA

304 measurements are often not possible in these patients. We present encouraging preliminary

305 results with an original questionnaire, specifically designed for children with visual

306 impairment and associated sensory, motor and/or cognitive disabilities. The relatively good

307 visual skills of the patients in this series contrast with the often-pessimistic conclusions from

308 initial ophthalmological examinations. Ophthalmologists should not give a poor visual

309 prognosis to parents of a newborn recently diagnosed with CS and bilateral coloboma. They

310 should encourage parents to stimulate their child with lights and colored objects as much as

311 possible to foster the developmental of their social brain and visual cortex. 


\section{$312 \underline{\text { References }}$}

313 1. Blake KD, Prasad C. CHARGE syndrome. Orphanet J Rare Dis 2006; 1-34.

314 2. Verloes A. Updated diagnostic criteria for CHARGE syndrome: a proposal. Am J Med

315 Genet A 2005; 133A: 306-308.

316 3. Legendre M, Abadie V, Attié-Bitach T et al. Phenotype and genotype analysis of a French

317 cohort of 119 patients with CHARGE syndrome. Am J Med Genet C Semin Med Genet

$318 \quad 2017 ; 175:$ 417-430.

319 4. McMain K, Blake K, Smith I et al. Ocular features of CHARGE syndrome. J AAPOS Off

320 Publ Am Assoc Pediatr Ophthalmol Strabismus 2008; 12: 460-465.

321 5. Nishina S, Kosaki R, Yagihashi T et al. Ophthalmic features of CHARGE syndrome with

322 CHD7 mutations. Am J Med Genet A 2012; 158A: 514-518.

323 6. Russell-Eggitt IM, Blake KD, Taylor DS, Wyse RK. The eye in the CHARGE

324 association. Br J Ophthalmol 1990; 74: 421-426.

325 7. Strömland K, Sjögreen L, Johansson M et al. CHARGE association in Sweden:

326 malformations and functional deficits. Am J Med Genet A 2005; 133A: 331-339.

327 8. Tellier AL, Cormier-Daire V, Abadie V et al. CHARGE syndrome: report of 47 cases and

328 review. Am J Med Genet 1998; 76: 402-409.

329 9. Raqbi F, Le Bihan C, Morisseau-Durand MP, Dureau P, Lyonnet S, Abadie V. Early

330 prognostic factors for intellectual outcome in CHARGE syndrome. Dev Med Child Neurol $3312003 ; 45: 483-488$.

332 10. Salem-Hartshorne N, Jacob S. Adaptive behavior in children with CHARGE syndrome.

333 Am J Med Genet A 2005; 133A: 262-267.

334 11. Mackie RT, McCulloch DL. Assessment of visual acuity in multiply handicapped

335 children. Br J Ophthalmol 1995; 79: 290-296. 
336 12. Cochrane GM, Marella M, Keeffe JE, Lamoureux EL. The Impact of Vision Impairment

337 for Children (IVI_C): validation of a vision-specific pediatric quality-of-life questionnaire

338 using Rasch analysis. Invest Ophthalmol Vis Sci 2011; 52: 1632-1640.

339 13. Felius J, Stager DR, Berry PM et al. Development of an instrument to assess vision-

340 related quality of life in young children. Am J Ophthalmol 2004; 138: 362-372.

341 14. Gothwal VK, Sumalini R, Bharani S, Reddy SP, Bagga DK. The second version of the L.

342 V. Prasad-functional vision questionnaire. Optom Vis Sci Off Publ Am Acad Optom 2012;

343 89: 1601-1610.

344 15. Katsumi O, Chedid SG, Kronheim JK, Henry RK, Jones CM, Hirose T. Visual Ability

345 Score -- a new method to analyze ability in visually impaired children. Acta Ophthalmol

346 Scand 1998; 76: 50-55.

347 16. Khadka J, Ryan B, Margrain TH, Court H, Woodhouse JM. Development of the 25-item

348 Cardiff Visual Ability Questionnaire for Children (CVAQC). Br J Ophthalmol 2010; 94 :

$349730-735$.

350 17. Pueyo V, García-Ormaechea I, González I et al. Development of the Preverbal Visual

351 Assessment (PreViAs) questionnaire. Early Hum Dev 2014; 90: 165-168.

352 18. Tadić V, Cooper A, Cumberland P, Lewando-Hundt G, Rahi JS, Vision-related Quality

353 of Life Group. Development of the functional vision questionnaire for children and young

354 people with visual impairment: the FVQ_CYP. Ophthalmology 2013; 120 : 2725-2732.

355 19. Ferziger NB, Nemet P, Brezner A, Feldman R, Galili G, Zivotofsky AZ. Visual

356 assessment in children with cerebral palsy: implementation of a functional questionnaire.

357 Dev Med Child Neurol 2011; 53: 422-428.

358 20. McCulloch DL, Mackie RT, Dutton GN et al. A visual skills inventory for children with

359 neurological impairments. Dev Med Child Neurol 2007; 49: 757-763.

360 21. Olsen TW, Summers CG. Predicting visual acuity in eyes with fundus colobomas: optic

361 nerve involvement, size, or the fovea? Ophthalmology 1997; $104: 1367-1368$. 
Table 1: Comparison of the 36 responders to the VISIOCHARGE questionnaire and the total number of CHARGE syndrome patients followed in our center

\begin{tabular}{|c|c|c|c|}
\hline & $\begin{array}{c}\text { Charts } \\
\text { reviewed } \\
n=83\end{array}$ & $\begin{array}{l}\text { VISIOCHARGE } \\
\text { responders } \\
n=36\end{array}$ & $\mathrm{p}$ \\
\hline $\begin{array}{l}\text { Sex, n patients }(\%) \\
\text { Male } \\
\text { Female }\end{array}$ & $\begin{array}{l}46(55) \\
37(45)\end{array}$ & $\begin{array}{l}18(50) \\
18(50)\end{array}$ & 0.69 \\
\hline \multicolumn{4}{|l|}{ Ocular features, n patients (\%) } \\
\hline Posterior coloboma & $69(83)$ & $32(89)$ & \multirow[t]{3}{*}{0.58} \\
\hline - unilateral & $14(17)$ & 7 (19) & \\
\hline - bilateral & $55(66)$ & $25(69)$ & \\
\hline Iris coloboma & $12(14)$ & 7 (19) & \multirow[t]{3}{*}{0.59} \\
\hline - unilateral & $6(7)$ & $3(8)$ & \\
\hline - bilateral & $6(7)$ & $4(11)$ & \\
\hline Microphtalmos & $28(34)$ & $15(42)$ & \multirow[t]{3}{*}{0.41} \\
\hline - unilateral & $25(30)$ & $13(36)$ & \\
\hline - bilateral & $3(4)$ & $2(6)$ & \\
\hline Ptosis & $14(17)$ & 7 (19) & 0.80 \\
\hline Nystagmus & $24(29)$ & $11(31)$ & 1 \\
\hline Facial palsy & $24(29)$ & $10(28)$ & 1 \\
\hline Congenital cataract & $4(5)$ & $1(3)$ & 1 \\
\hline - unilateral & $3(4)$ & $1(3)$ & \multirow{5}{*}{0.49} \\
\hline - bilateral & $1(1)$ & 0 & \\
\hline Retinal detachment & $6(7)$ & $4(11)$ & \\
\hline - unilateral & $6(7)$ & $4(11)$ & \\
\hline - bilateral & 0 & 0 & \\
\hline Severity of the coloboma* & & & \multirow[t]{4}{*}{0.55} \\
\hline Group A, n patients (\%) & $42(51)$ & $18(50)$ & \\
\hline Group $\mathrm{B}, \mathrm{n}$ patients $(\%)$ & $36(43)$ & $17(47)$ & \\
\hline Unclassified & $5(6)$ & $1(3)$ & \\
\hline Age of walking (months) & & & \multirow{3}{*}{0.66} \\
\hline Mean (SD) & $36.9(15.7)$ & $35.4(15.0)$ & \\
\hline Min-max & $19-78$ & $19-78$ & \\
\hline Visual acuity (decimal): & & & \multirow{3}{*}{0.97} \\
\hline Mean & 0.41 & 0.42 & \\
\hline Unmeasurable & $48(58)$ & $16(44)$ & \\
\hline
\end{tabular}

*Group A, patients with no coloboma in both eyes or with coloboma in one or both eyes but at least 


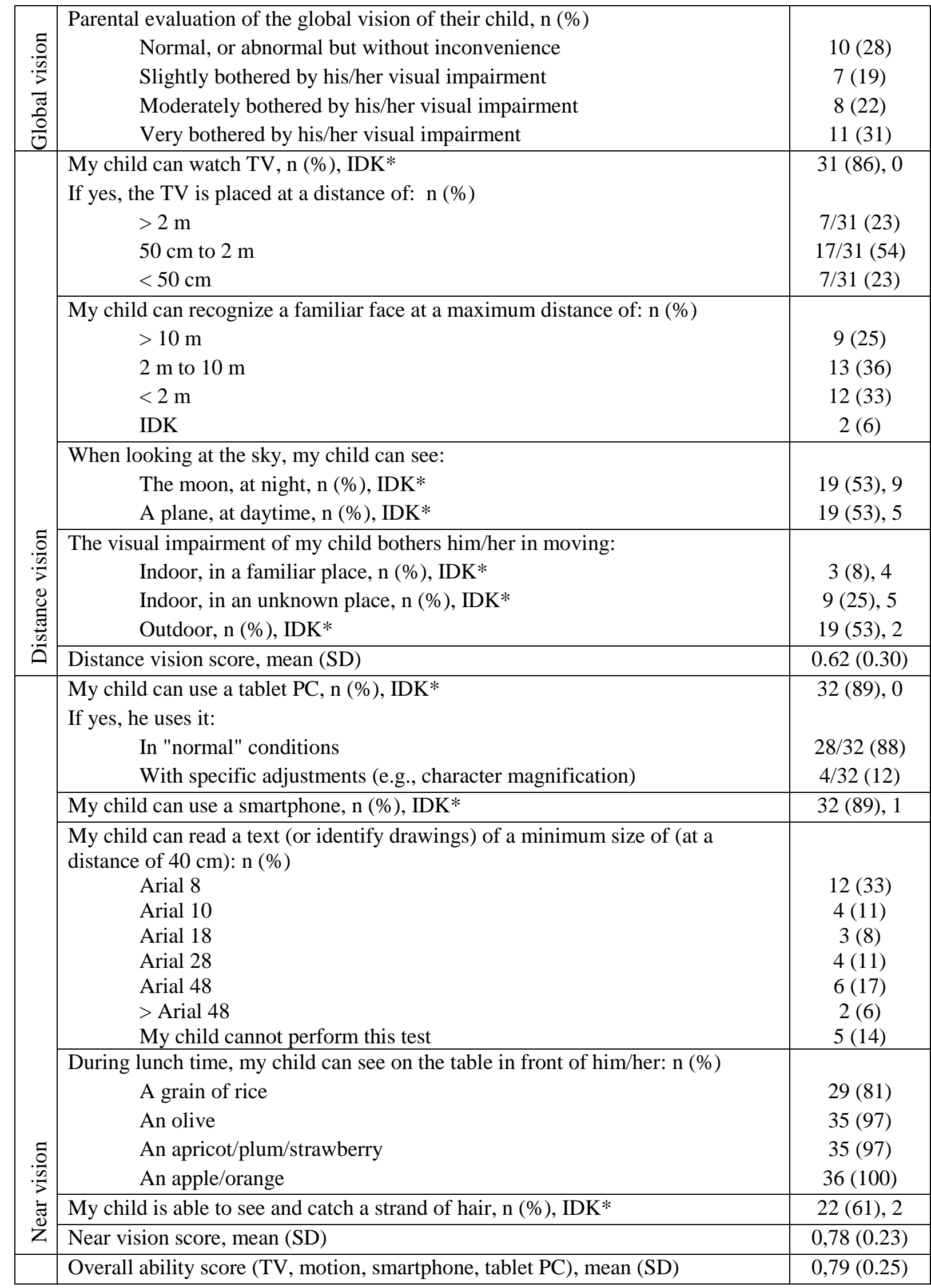

* IDK: I don’t know 
375 Table 3: Comparison of visual and developmental features by severity of the 376 colobomatous malformation: Group A and B patients

\begin{tabular}{|l|c|c|c|}
\hline & $\begin{array}{c}\text { Group A* } \\
(\mathrm{n}=18)\end{array}$ & $\begin{array}{c}\text { Group B* } \\
(\mathrm{n}=17)\end{array}$ & $\mathrm{p}$ \\
\hline Age (years), mean (SD) & $13.1(6.8)$ & $14.7(7.3)$ & 0.50 \\
\hline Parental evaluation of the overall vision of their child, $\mathrm{n}(\%)$ & & & 0.07 \\
Normal, or abnormal but without inconvenience & $8(44)$ & $2(12)$ & \\
Slightly bothered by his/her visual impairment & $2(11)$ & $5(29)$ & \\
Moderately bothered by his/her visual impairment & $5(28)$ & $3(18)$ & \\
Very bothered by his/her visual impairment & $3(17)$ & $7(41)$ & \\
\hline Visual acuity (LogMar), mean (SD) & $0.05(0.10)$ & $0.64(0.28)$ & $<\mathbf{0 . 0 0 1}$ \\
\hline Distance-vision score, mean (SD) & $0.71(0.31)$ & $0.54(0.27)$ & $\mathbf{0 . 0 4 9}$ \\
\hline Near-vision score, mean (SD) & $0.88(0.20)$ & $0.69(0.22)$ & $\mathbf{0 . 0 0 8}$ \\
\hline Overall ability score, mean (SD) & $0.83(0.20)$ & $0.76(0.30)$ & 0.64 \\
\hline Age of walking (months), mean (SD) & $34.7(15.9)$ & $36.2(15.1)$ & 0.79 \\
\hline
\end{tabular}

* Group A, no coloboma in both eyes or with a coloboma in one or both eyes but at least one eye 
Table 4: Comparison of existing questionnaires evaluating visual function and visual disability in children

\begin{tabular}{|c|c|c|c|c|c|}
\hline & $\begin{array}{l}\text { Age } \\
\text { range } \\
\text { (years) }\end{array}$ & Target children & $\begin{array}{c}\text { Person } \\
\text { interviewed }\end{array}$ & $\begin{array}{l}\text { No. of } \\
\text { items }\end{array}$ & $\begin{array}{l}\text { Evaluated } \\
\text { parameters }\end{array}$ \\
\hline $\mathrm{VAS}^{\mathrm{a}}$ & $2-18$ & $\begin{array}{l}\text { Children with visual } \\
\text { impairment with no other } \\
\text { sensorial, physical or } \\
\text { cognitive disability }\end{array}$ & Parents & 16 & $\begin{array}{l}\text { Visual acuity, } \\
\text { visual field, } \\
\text { color vision }\end{array}$ \\
\hline $\mathrm{CVFQ}^{\mathrm{b}}$ & $\leq 7$ & $\begin{array}{l}\text { Children with visual } \\
\text { impairment with or } \\
\text { without developmental } \\
\text { delay }\end{array}$ & Parents & 40 & $\begin{array}{l}\text { Personal, social } \\
\text { and familial } \\
\text { impact of visual } \\
\text { disability }\end{array}$ \\
\hline $\mathrm{CVAQC}^{\mathrm{c}}$ & $5-18$ & $\begin{array}{l}\text { Children with acquired } \\
\text { spoken language and no } \\
\text { sensorial, physical or } \\
\text { cognitive disability }\end{array}$ & Child & 25 & $\begin{array}{l}\text { Ability to } \\
\text { complete tasks } \\
\text { requiring vision }\end{array}$ \\
\hline IVI_C ${ }^{d}$ & $8-18$ & $\begin{array}{l}\text { Children with visual } \\
\text { impairment with acquired } \\
\text { spoken language and no } \\
\text { other sensorial, physical } \\
\text { or cognitive disability }\end{array}$ & Child & 24 & $\begin{array}{l}\text { Personal, social } \\
\text { and scholar } \\
\text { impact of visual } \\
\text { disability }\end{array}$ \\
\hline LVP_FVQ II $^{\mathrm{e}}$ & $8-18$ & $\begin{array}{l}\text { Children in developing } \\
\text { countries with acquired } \\
\text { spoken language and no } \\
\text { sensorial, physical or } \\
\text { cognitive disability }\end{array}$ & Child & 23 & $\begin{array}{l}\text { Grading of } \\
\text { visual } \\
\text { impairment }\end{array}$ \\
\hline FVQ_CYP & $10-15$ & $\begin{array}{l}\text { Children with acquired } \\
\text { spoken language and no } \\
\text { sensorial, physical or } \\
\text { cognitive disability }\end{array}$ & Child & 36 & $\begin{array}{l}\text { Ability to } \\
\text { complete tasks } \\
\text { requiring vision }\end{array}$ \\
\hline PreViAs ${ }^{g}$ & $\leq 2$ & $\begin{array}{l}\text { Babies, except premature } \\
\text { infants, without a "major" } \\
\text { adverse medical history or } \\
\text { developmental delay }\end{array}$ & Parents & 30 & $\begin{array}{l}\text { Reactions of the } \\
\text { infant to visual } \\
\text { stimulations }\end{array}$ \\
\hline
\end{tabular}

${ }^{a}$ Visual Ability Score (Katsumi et al., 1998)

387 'Children's Visual Function Questionnaire (Felius et al., 2004)

$388{ }^{\circ}$ Cardiff Visual Ability Questionnaire for Children (Khadka et al., 2010)

389 dimpact of Vision Impairment for Children (Cochrane et al., 2011)

390 e.V. Prasad - Functional Vision Questionnaire (Gothwal et al., 2012)

391 fFunctional Vision Questionnaire for Children and Young People (Tadic et al., 2013)

392 gPreverbal Visual Assessment questionnaire (Pueyo et al., 2014) 
Click here to access/download Supplemental Material / Data

Martin VISIOCHARGE QUESTIONNAIRE English.pdf 
Click here to access/download Author Statement/ICMJE Form Disclosure BODAGHI.pdf 
Click here to access/download Author Statement/ICMJE Form Disclosure ABADIE.pdf 
Click here to access/download Author Statement/ICMJE Form Disclosure BREMONDGIGNAC.pdf 
Click here to access/download Author Statement/ICMJE Form Disclosure CHALLE.pdf 
Click here to access/download Author Statement/ICMJE Form Disclosure MARTIN.pdf 
Click here to access/download Author Statement/ICMJE Form Disclosure ATTIEBITACH.pdf 
Click here to access/download Author Statement/ICMJE Form Disclosure ROBERT.pdf 
Click here to access/download Author Statement/ICMJE Form Disclosure TRINH.pdf 